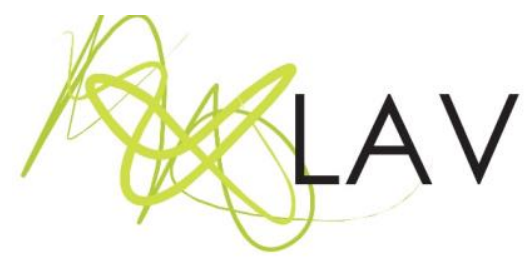

\title{
Caminhos de uma pesquisa: a costurografia como outra escrita acadêmica
}

Paths of a research: the costurography as another academic writing

Anelice Ribetto ${ }^{i}$

Universidade do Estado do Rio de Janeiro

Rejane Nascimentoii

Universidade do Estado do Rio de Janeiro

\section{Resumo}

Este trabalho intenta trazer uma conversa entre uma estudante e uma professora de um programa de Pós-Graduação em Educação a experiência de uma pesquisa. Apostando em outros contornos metodológicos acontece um deslocamento da produção conceitual da própria escrita. Escrever como costurar. No percurso da pesquisa, a estudante, começa a problematizar a escrita acadêmica como empreitada coletiva, como aposta política, ética e estética. Neste percurso cartografado, a costurografia como manualidade, como um dispositivo. Uma escrita feita à mão, com linhas, agulha e retalhos de jeans. A partir de restos, a costurografia se compõe no tecido e também em outras superfícies possíveis. Feita no jeans e no papel. Gestos mínimos, ínfimos. Uma escrita experimentação.

Palavras-chave: escrita acadêmica, cartografia, dispositivo, costurografar, costurografia.

\section{Abstract}

This work tries to bring a conversation between a student of Academic Master's in Education, one professor and the experience of a research. Betting on other methodological contours happens a displacement of the conceptual production of the own writing. Write how to sew. In the course of the research, the student begins to problematize academic writing as a collective undertaking, as a political bet, ethics and aesthetics. In this mapped course, the costurography as a craft. Handwriting, with lines, needle and patchwork of jeans. From the remains, the costurography is composed in the fabric and also in other possible surfaces. Made in jeans and paper. Minimal, small gestures. A writing experimentation.

Keywords: academic writing, cartography, device, sewing, costurography.

\section{Introdução}

Este texto é uma grande conversa porque se desdobra, desloca e de algum modo busca tocar o que se tem no íntimo, trazendo nesta trama da escrita a costura de linhas que coemergem dos agenciamentos entre as autoras, seus gestos mínimos, apenas tateados e outros interlocutores, que compõem outras 
possibilidades de pensar a escrita acadêmica. É também conversa porque busca, hospedada em outras palavras como amorosidade e amizade, se aproximar do acariciar, do deslizar, acompanhar e também do alterar e incidir (SKLIAR, 2011, p. 27).

Uma conversa entre uma estudante de Mestrado Acadêmico em Educação, uma Professora Doutora em Educação e a experiência de uma pesquisa que se dá através de um dispositivo de encontros e, então, dispositivo-problematização, que chamamos de Orientação Coletiva, acompanhada pelas implicações do/no campo de pesquisa. Esta produção se dá no corpo de um coletivo de forças chamado Diferenças e Alteridade na Educação, criado em 2011 e que, atualmente, reúne professoras de escolas de ensino fundamental, professores e estudantes da Faculdade de Formação de Professores da Universidade do Estado de Rio de Janeiro, gestores de políticas públicas inclusivas nas escolas e famílias principalmente mães - de chamados estudantes com deficiências. Esse coletivo assume algumas questões que compõem os nossos maiores desafios: primeiro, sustentarmos que os saberes e conhecimentos sobre o mundo se produzem rizomaticamente. Vivemos em redes que conectam e agenciam saberes múltiplos e nos contrapomos à defensa de que a universidade deve, apenas, contentar-se com a produção de um conhecimento científico - aparentemente - produzido fora destas redes. Não há fora e dentro dessas redes, há, apenas, redes. Assim, apostamos na produção de saberes entre professores-alunos-de-escola-deuniversidades-famílias-gestores-de-políticas-públicas. Claro que isto demanda a negociação contínua dos sentidos ali produzidos, porque mobilizam fluxos de poderes e saberes. Segundo, nesta rede, problematizamos a produção da normalidade como política presente no campo da pedagogia e que ainda contribui para a exclusão e massacre de pessoas que se afastam da norma criada como vetor de padronização e, terceiro, como efeito disso, e, coerente com essa problematização da norma no corpo, colocamos também em questão as formas com que as pedagogias vêm narrando o outro: a partir de um discurso medicalizado (os rótulos...) ou marcadamente judicializado (o discurso do direito como discurso apenas jurídico) para afirmar, a partir do coletivo, a invenção de uma narrativa que revele o encontro ético com o outro. Para isso, criamos uma diversidade de dispositivos que nos permitem contar esse encontro de alteridade que se encarna na relação com essas pessoas que foram historicamente produzidas como "anormais", já que problematizam radicalmente a "congruência" dos corpos. E a congruência da escrita? Não se trata, pois, de escrever sobre um tema, uma questão, um objeto, um problema. Trata-se de expor os caminhos que o encontro e 
com o tema-objeto-problema-questão provoca em (nós)outros e o que fazemos com isso. Assim, afirmamos a escrita de diários, biografemas, crônicas, ensaios, a produção de paisagens sonoras, etc., como uma expressão da aposta na micropolítica da diferença que se narra com outros contornos metodológicos.

\section{A Costurografia como outra escrita acadêmica}

Outros contornos metodológicos supõem, para nós, outras apostas escriturísticas que se inventam conversando e apresentando um convite que não pretende explicar nem compreender os caminhos da escrita, mas que se propõe a problematizar o próprio gesto e a escapar pelas brechas, em um devir que vai se dando a partir de outros gestos na pesquisa. Escrever como costurar.

A estudante já era costureira. Aprendeu a costurar com sua mãe. Depois disso formou-se professora. A chegada ao Mestrado em 2016 e as experiências com o Coletivo, a afetaram e com isso, a costura que já fazia parte de sua vida, se apresentou como um modo pelo qual ela poderia experimentar outra escrita na pesquisa que intitulamos provisoriamente como Costurografando e Problematizando a relação entre uma mãe e seu filho chamado pessoa com deficiência intelectual.

Esse tipo de escrita, que foge de certezas, que impõe
compromissos de divulgá-la, ensiná-las e prescrevê-las,
reconhece que os conhecimentos que fomos elaborando
exigem sempre de nós um estranhamento maior na vida,
perscrutando suas pulsações e potências, interstícios e
capilaridades que nos transfiguram, quando as
transfiguramos ao escrever (LINHARES, 2016, p. 8).

Costurar para falar de vida. Este movimento que envolve todo corpo e que através da manualidade, aproximaria o ato de costurar do escrever. Primeiro pensamos no verbo chulear. A costura como o chulear. A escrita como chulear. $O$ ponto de chulear a mão é sempre irregular. Eles são singulares e saltam à borda do tecido, a circulam para não desfiar. O chulear e o bordar a mão. Uma mistura entre os dois. "Uma criação que obedece a outras lógicas e sentidos" (RIBETTO, 2014, p. 96). Algo que não é completamente nem um ou outro. Entre os dois para ganhar velocidade. Fazer vibrar o que se sentia. Tencionar e problematizar esta costura outra, que se aproximava da escrita experimentada. Então foi feita uma escolha, apostando que ao invés de se costurar na borda, fizesse isso no meio do tecido. Os pontos irregulares do chulear e alguns outros pontos de bordado a mão para costurar as palavras. Uma composição entre costura e escrita. Gestos que trariam uma costura que não pertencesse a ela mesma. Algo incontrolável que a 
atravessava. Um eu representante de todos nós (ORLANDI, 2002), costurando... criando uma - a costurografia, pois

Apostamos em uma escrita potente, uma escrita da pesquisa que seja generosa: nosso desejo é espalhar essas linhas pela cidade, que essas folhas passem de mão em mão, que circulem pelos espaços, que possam ser lidas por qualquer um (MACHADO; ALMEIDA, 2016, p. 78).

Inicialmente a proposta de compor uma pesquisa autobiográfica que apostasse nos efeitos produzidos na relação entre mãe e filho se revelou como um grande desafio, pois não se tratava apenas de narrar uma história de vida, mas buscar no entre desta relação o que Deleuze e Guattari apontam:

Entre as coisas não designa uma correlação localizável que vai de uma para outra e reciprocamente, mas uma direção perpendicular, um movimento transversal que as carrega uma e outra, riacho sem início nem fim, que rói suas duas margens e adquire velocidade no meio (DELEUZE; GUATTARI, 1995, p. 04).

Foi preciso então encontrar pistas, tateando, com olhar sensível, disponível para buscar o que se passava. As experiências singulares que reverberavam coletivamente, através de uma escrita que produzisse sentidos, continuidades e descontinuidades. Para dizer sem esvaziar-se por completo. O corpo, a mão, a linha, a agulha, a escrita costurografada, entrelaçada em palavras para narrar a história de uma mãe e se filho chamado pelos discursos médico e jurídico de pessoa com deficiência intelectual.

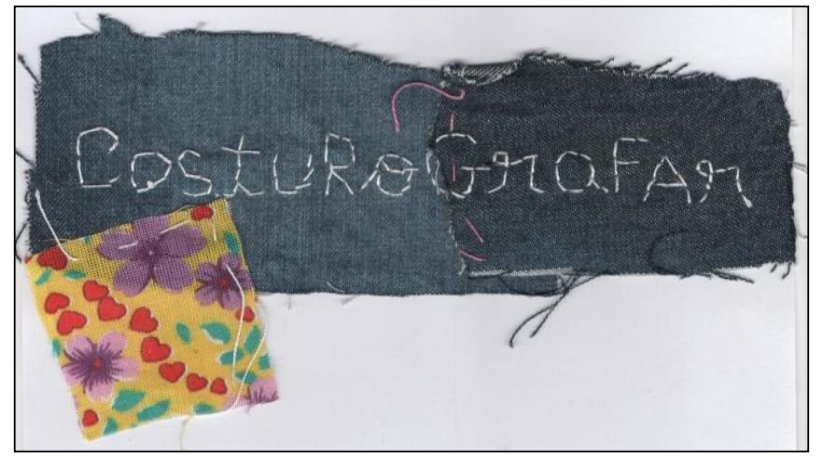

Figura 1

No percurso da pesquisa, a estudante, começou a problematizar a escrita acadêmica como empreitada coletiva, como aposta política, ética e estética, aproximando-se do ato de costurar, manualmente com linha e agulha. Aconteceu aí

Revista Digital do LAV - Santa Maria - vol. 10, n. 3, p. 05 - 16 - set./dez. 2017 ISSN 1983 - 7348 http://dx.doi.org/10.5902/1983734829916 
um deslocamento da produção conceitual da própria escrita e, com isso, o desejo de seguir apostando em criações singulares, tomou força.

De modo que no se trata aqui de pensar em uma escritura que tenga por objetivo darcuenta de lodicho, ni de lo por decir, de acuerdo a um plantrazado com anterioridad, sino de esa sola posibilidad de mostrarse transitória, ignorante, efectodel próprio devenir de um pensamento que corteja algunas ideias (VIGNALE, 2016, p. 69).

Os movimentos de uma pesquisa, no qual a proposta de escrita do texto era coletiva, cartografada (DELEUZE; GUATTARI, 1995), encaminhou para a criação de um verbete: costurografar. "No processo de pesquisa, os conceitos precisam ganhar consistência, incorporarem-se à vida do pesquisador e de seu campo problemático" (MACHADO; ALMEIDA, 2016, p. 77). Costurografar - Seguir costurografando palavras sentidas, de dentro, assim como os movimentos da pesquisa seguem cartografados, se entrecruzando com suas linhas de forças (DELEUZE, 1990), fazendo vibrar, problematizando a vida e apontando para outras possibilidades de escrita acadêmica. Com isso, afirmamos que "toda escritura se produce entre escrituras, de modo que no puede ser ceñida a uma escritura personal, que pretende uma potestade sobre la palavra (uma escritura es mía, propia, personal, me pertence)" (VIGNALE, 2016, p. 70). Para esta empreitada era preciso se assumir como uma pesquisadora-costureira. Costurografar a pesquisa para forjar encontros, conversar, para fazer novas escolhas, desformar e transformar a escrita em costurografias. Este movimento como algo que "força o pensamento a se derivar daquilo que já está colocado como verdade" (DIAS, 2014, p. 42).

\section{A costurografia do tecido ao papel - Uma escrita outra em superfícies possíveis}

Ser pesquisadora-costureira pelo meio, buscando o entre, sempre em vias de costura, de se diferir e se colocar atenta ao presente para compor outros modos de escrita (DIAS, 2014, p. 44). Neste percurso cartografado, a costurografia como manualidade. Uma escrita feita à mão, com linhas, agulha e retalhos de jeans. 0 que Manoel de Barros chamaria de apanhador de desperdícios, recolhendo os restos, daquele tecido - o jeans - já desgastado pelo tempo ou que caiu em desuso. Certamente este jeans seria descartado, jogado fora. Apesar disso, este mesmo tecido que vestiu corpos e que esteve em muitos lugares, mesmo sendo descartado, seguia repleto de histórias. É este tecido que interessa a costurografia. Seus usos e sentidos, suas linhas e tramas impregnadas do dizível e do indizível, 
mas que carrega em si suas marcas de ter coberto corpos, em movimento. "Essa criatividade resistente que possibilita outras (impensáveis) coisas a partir do que o poder hegemônico descarta como resto" (RIBETTO, 2014, p. 96).

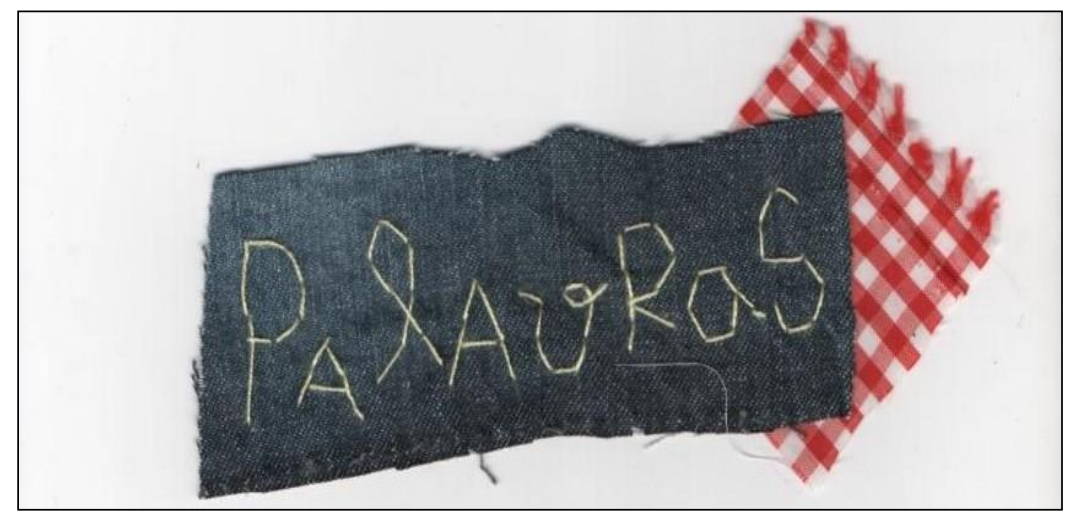

Figura 2

O apanhador de desperdícios

Uso a palavra para compor meus silêncios. Não gosto das palavras fatigadas de informar.

Dou mais respeito às que vivem de barriga no chão tipo água pedra sapo.

Entendo bem o sotaque das águas Dou respeito às coisas desimportantes e aos seres desimportantes. Prezo insetos mais que aviões. Prezo a velocidade das tartarugas mais que a dos mísseis. Tenho em mim um atraso de nascença.

Eu fui aparelhado para gostar de passarinhos. Tenho abundância de ser feliz por isso. Meu quintal é maior do que o mundo. Sou um apanhador de desperdícios: Amo os restos como as boas moscas.

Queria que a minha voz tivesse um formato 
de canto.

Porque eu não sou da informática:

eu sou da invencionática.

Só uso a palavra para compor meus silêncios.

Manoel de Barros

A partir de restos, a costurografia se compõe no tecido e também em outras superfícies possíveis. Feita no jeans e no papel. Gestos mínimos, ínfimos, que jorram do tecido e se aproximam do papel. Uma escrita experimentação (CLARETO; VEIGA, 2016, p. 32). Costurografar no papel? Sim! Do tecido ao papel para se compor uma pesquisa. Um dispositivo de escrita a partir do que Deleuze se refere: "O dispositivo, como sendo uma espécie de novelo ou meada, um conjunto multilinear" (1990, p.155) para dar a ver e falar palavras sentidas, de dentro. O próprio ato de costurografar que encerra em si linhas de força e subjetivação que se entrecruzam nas tramas da vida (CLARETO; VEIGA, 2016, p. 32). "A escrita como caminho do fazer, do dispositivo criado para fazer falar. Multiplicar as falas, instaurar acontecimentos nos quais o acontecer se dá" (CLARETO; VEIGA, 2016, p. 35).

Os retalhos que compõem este outro movimento de escrita costurografada no papel, se apresentam através da utilização de diversos tipos de fontes, que para além das normas hegemônicas para textos acadêmicos que recomendam as fontes Times New Roman e Arial, se apresentam como outras opções de uma escrita costurografada. Com isso, segue a escolha, política e estética que provoca, desestabiliza e dá abertura para que sejam feitas algumas perguntas sobre a escrita acadêmica. Uma escrita costurografada com diversas fontes, retalhos de escritaunidos, sobrepostos em conexão, em redes, muitas redes, outras redes que fazem o olhar saltar. Ela pode causar certo incômodo, nos tirando do lugar de uma escrita tranquilizadora, que segue as normas e aos padrões acadêmicos. Quais efeitos uma escrita costurografada pode produzir em mim, nos outros, em nós? Nós? Os efeitos naquilo que sou, que vou me tornando (ORLANDI, 2002).

Outra aposta da costurografia é trazê-la como experiência de alteridade, para se pensar sobre coisas que não havíamos pensado antes, sentir coisas que nos passam despercebidos. Outra coisa que não sou eu, mas que me atravessa, me afeta e que me faz perceber que toda esta experiência de escrita se passa em mim, no meu corpo disponível (LARROSA, 2002). "Não se trata de escrever sobre, mas de escrever na. Escrever na experiência" (RIBETTO, 2016, p. 59). Um novo convite

Revista Digital do LAV - Santa Maria - vol. 10, n. 3 p. 05 - 16 - set./dez. 2017 ISSN 1983 - 7348 http://dx.doi.org/10.5902/1983734829916 
por instantes, ínfimos, que podem fazer nosso olhar capturar os detalhes que às vezes nos escapam. Escrever subvertendo a escrita, não tem relação aqui com a mera atitude de romper regras. Consideramos a importância da escrita produzida na Academia, mas atentamos, a partir de deslocamentos conceituais de escrita, que é possível compor textos acadêmicos, também válidos, utilizando outros modos de escrita. "Porque la escritura no debiera nunca buscar um destino, sino afirmar um trânsito hacia" (VIGNALE, 2016, p. 70). Escrever com fragmentos, restos, tecido e papel costurografados na manualidade, nas fontes variadas que buscam transitar entre a experiência individual, o que toma força e reverbera no coletivo. Uma tarefa que demanda grande esforço, pois o corpo implicado, na pesquisa-costurografada, revela o desejo-desejos de trazer uma escrita que transfigure a vida. Para isso talvez seja preciso também "caçar palavras que atravessam as próprias palavras" (PÉREZ, 2014, p. 110). Seguir pensando nos limites e deslimites de uma escrita.

\section{A costurografia como um dispositivo na pesquisa}

Ao lançar mão da costurografia como um dispositivo na pesquisa, que utiliza um jogo de forças entre linha e corpo, agulha e mão, papel e tecido, muitas tensões e jogos de poder vão sendo forjados no percurso desta escrita-pesquisa repleta de elementos que seguem direções distintas, que produzem efeitos, afetam, são afetadas e formam processos sempre em desequilíbrio (DELEUZE, 1990). Se torna um objeto visível, que traz enunciações formuláveis, forças em exercício e sujeitos (DELEUZE, 1990). Renunciar que existe um modo único de escrever, retomando uma discussão metodológica sobre o campo da pesquisa em educação, não implica cair em um abismo do sem sentido, sem chão. O desejo de abrir-se à multiplicidade, para "conversar, talvez, sobre o que fazemos, sobre o que nos passa naquilo que fazemos [..]" (SKLIAR, 2011, p. 29), instigando outros pesquisadores e também leitores que se suspendam algumas certezas, abrindo-se para outras possibilidades, nos mobiliza a seguir problematizando o campo da escrita acadêmica. "É preciso estar munido de um espanto de existir para aventurar-se" (GERALDI, 2004, p. 602).

Costurografar para escrever juntando retalhos de vida, o que jorra de dentro, potente, que ganha força do singular para o coletivo. Uma escrita que acontece em vias de se mostrar, que quer dar a ver falar, que opera o visto e o não visto, produzindo efeitos na relação constante de forças sempre em desequilíbrio. (DELEUZE, 1990). "Uma escrita que não domestica" (MACHADO; ALMEIDA, 2016,

Revista Digital do LAV - Santa Maria - vol. 10, n. 3, p. 05 - 16 - set./dez. 2017 ISSN 1983 - 7348 http://dx.doi.org/10.5902/1983734829916 
p. 80). Para ser singular e plural, múltiplo e mínimo. A vida como uma experiência. A costurografia como um modo de pesquisa-experimentação.

\section{Considerações finais}

A costurografia como uma proposta de escrita e como um contorno metodológico outro no campo da educação "se dá por múltiplas entradas. O texto se apresenta na forma convidativa de uma conversa sem fim" (CLARETO; VEIGA, 2016 , p. 31). Escrever costurografando na manualidade dos gestos se transfigura em uma escrita feita de múltiplos afetos. Um dispositivo-problematização que atravessa o corpo que a compõe, que produz efeitos no individual e que jorram para o coletivo. A escrita de um que jorra em muitos, guardando pedaços de coisas que foram costurografadas no tecido ou no papel.

Escrever é um caso de devir, sempre inacabado, sempre em via de fazer-se, e que extravasa qualquer matéria visível ou vivida. É um processo, ou seja, uma passagem de vida que atravessa o vivível e o vivido (DELEUZE, 2011, p. 11)

A aposta de uma escrita acadêmica outra, enfrentando os desafios de experimentar a pesquisa em educação, atenta aos estranhamentos e pensares sobre suas forças (DELEUZE, 1990). A costurografia para tremer o escrever, uma fazeção do pesquisar, como um modo de produção que vai se compondo entre o objeto e o campo de pesquisa. Pesquisar e escrever costurografando não dá para ser sobre, não pode ser mais do mesmo. Uma metodologia viva que pede uma escrita viva, que pulsa e atravessa. Produzir uma pesquisa na dinâmica do pesquisar, no engendra-se nos movimentos da costura. E assim criar brechas que nos permitam seguir sempre em suspeita, inquietos, deslocando-se a cada ponto de costura (CLARETO; VEIGA, 2016, p. 33-34).

Uma experiência de escrita na alteridade, em certa composição provisória, porque não busca por respostas, mas tem o desejo de seguir perguntando, produzindo sentidos e efeitos em cada um, de modo singular. E chulear esses sentidos em um papel.

\section{Bibliografia}

BARROS, M. O apanhador de desperdícios. Disponível em: http://www.entreculturas.com.br/2010/10/manoel-de-barros-o-apanhador-de desperdicios/. 
CLARETO, S. M.; VEIGA, A. L. V. S. Uma escrita de muitos ou uma escrita em travessia. In: CALLAI, C. \& RIBETTO, A. (Org.). Uma escrita acadêmica outra: ensaios, experiências e invenções. Rio de Janeiro: Lamparina, 2016.

DELeUZE, Gilles; GuATTARI, Félix. Mil Platôs: Capitalismo e Esquizofrenia, v.1. Rio de Janeiro: Editora 34, 1995.

DELEUZE, G. O que é um dispositivo. (1990) Disponível em > file://C:/Users/User/Downloads/Gilles\%20Deleuze\%20\%200\%20que\%20e\%20u m\%20dispositivo\%20(1).pdf .

DELEUZE, Gilles. Crítica e Clínica. São Paulo: Editora 34, 2011.

DIAS, R. O. trajetórias poéticas por entre formação, arte e escola básica, in RIBETTO, Anelice (org). políticas, poéticas e práticas pedagógicas (com minúsculas). 1. ed. Rio de Janeiro: Lamparina, FAPERJ, 2014.

GERALDI, João Wanderley. Pelos caminhos e descaminhos dos métodos. Educação e Sociedade, Campinas, v. 25, n.87, p. 601-610, 2004.

LARROSA, Jorge. Notas sobre experiência e o saber de experiência. In: Revista Brasileira de Educação. n. 19. São Paulo, p. 20 - 28, jan/fev/mar/abr, 2002.

LINHARES, L. Escrever e viver: estranhamentos e entranhamentos recíprocos, in CALLAI, C. \& RIBETTO, A. (Org.). Uma escrita acadêmica outra: ensaios, experiências e invenções. Rio de Janeiro: Lamparina, 2016.

MACHADO, L. D.; ALMEIDA, L. P. Notas sobre escrever [n] uma vida. In CALLAI, C. \& RIBETTO, A. (Org.). Uma escrita acadêmica outra: ensaios, experiências e invenções. Rio de Janeiro: Lamparina, 2016.

ORLANDI, L.B.L. (2002) Que estamos ajudando a fazer de nós mesmos? In: M. Rago, L.B.L. Orlandi \& A. V. Neto (orgs.) Imagens de Foucault e Deleuze ressonâncias nietzscheanas (v.1, p. 227-238). Rio de Janeiro: DP\&A, 2002.

Revista Digital do LAV - Santa Maria - vol. 10, n. 3, p. 05 - 16 - set./dez. 2017 ISSN 1983 - 7348 http://dx.doi.org/10.5902/1983734829916 
PÉREZ, C. L. V. cinco cabeças e um copo de café... (com)fabulações sobre a potência de uma educação menor, in RIBETTO, A. (Org.). políticas, poéticas e práticas pedagógicas (com minúsculas). 1. ed. Rio de Janeiro: Lamparina, FAPERJ, 2014.

RIBETTO, A. Experiência, experimentações e restos na escrita acadêmica. In: CALLAI, C.; RIBETTO, A. (Org.). Uma escrita acadêmica outra: ensaios, experiências e invenções. Rio de Janeiro: Lamparina, 2016.

RIBETTO, A. dos saberes risíveis aos saberes menores na educação. RIBETTO, A. (org). políticas, poéticas e práticas pedagógicas (com minúsculas). 1. ed. Rio de Janeiro: Lamparina, FAPERJ, 2014.

SKLIAR, Carlos. Conversar e conviver com os desconhecidos. In: FONTOURA, Helena Amaral da (Org.). Políticas Públicas, Movimentos Sociais: Desafios à Pósgraduação em Educação em suas múltiplas dimensões. Rio de Janeiro: ANPEd Nacional, 2011. Modo de acesso: Disponível em: http://www.fe.ufrj.br/anpedina2011/livro3.pdf.

VIGNALE, S. Prefacio para uma política de la escritura In: CALLAI, C.; RIBETTO, A. (Org.). Uma escrita acadêmica outra: ensaios, experiências e invenções. Rio de Janeiro: Lamparina, 2016.

i Professora adjunta da Universidade do Estado do Rio de Janeiro e pesquisadora procientista da mesma instituição. Lotada no Departamento de Educação da Faculdade do Formação de Professores (UERJ/FFP/DEDU) participa de projetos de ensino, pesquisa e extensão na Licenciatura em Pedagogia e atua como professora efetiva e coordenadora no Programa de Pós-Graduação Mestrado em Educação - Processos formativos e desigualdades sociais na Linha Políticas, Direitos e Desigualdades. Faz parte do Coletivo Diferenças e Alteridade na Educação; coordenando o Projeto de Pesquisa Tensões entre políticas e experiências na rede municipal de ensino de São Gonçalo e faz parte do Grupo de Pesquisa Vozes da Educação (CNPq) Se interessa pelas políticas, poéticas e práticas na/da diferença, alteridade e experiência na educação, e na produção de políticas narrativas outras para contar a prática e a pesquisa em educação. Graduada em psicologia pela Universidade Nacional de Córdoba/Argentina (1991) e Doutora em Educação pela Universidade Federal Fluminense/Brasil (2009)

ii Possui graduação em Pedagogia pela Universidade do Estado do Rio de Janeiro- UERJ (2004), Pós-graduação em Psicopedagogia (2007), Gestão Escolar- Especialização em Educação Básica (2007) e Gestão Educacional- Administração, Supervisão e Orientação Educacional (2011). É Mestranda em Educação da FFP / UERJ (PPG-EDU Processos Formativos e Desigualdades Sociais). É professora das Séries Iniciais, Orientadora Educacional da Rede Municipal de Maricá, Tutora do FNDE (EAD) - Programa Formação pela Escola e atualmente integra a Equipe de Assessoria de Projetos, Programas Federais e Formação Continuada da Secretaria Municipal de Educação de Maricá. É membro do Grupo de Pesquisa Coletivo Diferenças e Alteridade em Educação que reúne professores da escola básica, professores e estudantes da Faculdade de Formação de Professores da UERJ,

Revista Digital do LAV - Santa Maria - vol. 10, n. 3 p. 05 - 16 - set./dez. 2017 ISSN 1983 - 7348

http://dx.doi.org/10.5902/1983734829916 
gestores das redes públicas de ensino e famílias - principalmente mães- de alunos ditos pessoas com deficiência. É pesquisadora na área de Educação Especial na perspectiva da Educação Inclusiva. Já atuou como Implementadora e Surpervisora de Educação Especial e como Coordenadora Municipal de Atendimento Pedagógico Domiciliar (APD). Ministra cursos de formação, palestras na área da Educação Especial/Inclusiva e programas do FNDE.

Como citar esse artigo:

RIBETTO, Anelice; NASCIMENTO, Rejane. Caminhos de uma pesquisa: a costurografia como outra escrita acadêmica. Revista Digital do LAV, Santa Maria: UFSM, v. 10, n. 3, p. 05-16, set./dez. 2017.

Enviado em: 09 de novembro de 2017.

Aprovado em: 30 de novembro de 2017. 